E. coli variability in fresh dairy faeces

This is the peer reviewed version of the following article: Oliver, D.M. (2014), Seasonal and within-herd variability of E. coli concentrations in fresh dairy faeces. Letters in Applied Microbiology, 59: 86-92, which has been published in final form at http://onlinelibrary.wiley.com/doi/10.1111/lam.12248/full. This article may be used for non-commercial purposes in accordance With Wiley Terms and Conditions for self-archiving 


\title{
Seasonal and within-herd variability of $E$. coli concentrations in fresh dairy faeces
}

\author{
David M Oliver \\ Biological and Environmental Sciences \\ School of Natural Sciences \\ University of Stirling \\ Stirling \\ FK9 4LA \\ UK
}

Corresponding author: david.oliver@stir.ac.uk, Biological \& Environmental Sciences, School of Natural Sciences, University of Stirling, Scotland, UK. Tel: +44 1786 467846; Fax: +44 1786467843. 


\section{E. coli variability in fresh dairy faeces}

\section{Significance and impact of the study}

52 This study provides a comprehensive temporal dataset of faecal indicator organism

53 (FIO) counts (both E. coli and other coliforms) in fresh dairy faeces for Scotland.

54 Such faecal audits for the UK are scarce which is surprising given that livestock

55 constitute one of the largest agricultural sources of diffuse microbial pollution of 56 surface waters and contributors to poor bathing water quality. Such FIO 57 concentration data (and evaluation of variability across seasonal, within-herd, and 58 year-on-year counts) in fresh faeces is a fundamental precursor to the robust 59 parameterization of models that aim to predict the fate and transfer of both FIOs and 60 pathogens in agricultural catchments.

\section{Abstract}

63 The aim of this study was to determine concentrations of culturable faecal indicator 64 organisms (FIOs) in freshly excreted dairy faeces and assess seasonal, within-herd and year-on-year variability in counts. Such values are essential in order to provide input parameters and associated uncertainty bounds for empirical models designed

67 to determine the burden of FIOs on pasture. A longitudinal faecal analysis survey $68(\mathrm{n}=80)$ was conducted at a conventional dairy farm in central Scotland over a two69 year period. The analysis quantified counts of Escherichia coli and other non-E. coli 70 coliforms and compared the concentrations of these FIO groups across contrasting 71 seasons. The overall mean concentration of E. coli was 6.63 and $6.58 \log _{10}$ CFU g ${ }^{-1}$ 72 dry weight in 2012 and 2013, respectively. However, concentrations of E. coli in 73 faecal pats on each seasonal sampling event were highly variable and spanned 74 several orders of magnitude on all occasions. Concentrations of E. coli in faeces 75 excreted in winter were found to be lower than those excreted in all other seasons in 76 2012, though patterns of seasonal shedding were not consistent in observations the 
E. coli variability in fresh dairy faeces

following year highlighting additional sources of uncertainty in FIO loading to land from dairy herds.

Keywords: agriculture; cattle; diffuse pollution; Escherichia coli; faecal coliforms; livestock faeces; modelling

\section{Introduction}

Escherichia coli are commonly used as a faecal indicator organism (FIO) by environment protection agencies throughout the world. While the presence (or absence) of FIOs does not confirm the presence (or absence) of a pathogen (Wu et al., 2011) their detection in environmental matrices is indicative of pollution originating from a faecal source (Blaustein et al., 2013). These bacteria, which make up the majority of the faecal coliform (FC) group, can be released into the wider environment following livestock defecation and/or manure and slurry applications to land, and via wastewater releases from sewage treatment works or septic tanks (Kay et al., 2008; Chadwick et al., 2009). In catchments dominated by livestock agriculture the accumulation of FIOs on pasture is a dynamic function of livestock numbers, their faecal excretion and bacterial shedding capacity, and bacterial die-off rates as determined by environmental drivers such as temperature and intensity of UV radiation (Oliver et al., 2010a).

The concentrations of $E$. coli found in freshly excreted livestock faeces can vary by several orders of magnitude (Cox et al, 2005; Muirhead et al., 2006; Ferguson et al., 2009). The drivers that contribute to this variation have been suggested to include diet, animal age, and livestock type, among other factors (Russell et al., 2000; Moriarty et al., 2008; Oliver et al., 2010b). This variability in shedding is not only linked to large scale faecal surveys across multiple farms, regions or countries; some 
E. coli variability in fresh dairy faeces

104 studies have reported large variation from within a single herd (e.g. Donnison et al., 105 2008).

107 This variation of $E$. coli shedding poses a significant challenge for the development of 108 modelling approaches to predict the fate and transfer of microbial contaminants 109 through agricultural catchments (Oliver et al., 2012). The growing requirement for the 110 design of 'programmes of measures' by Article 11 of the Water Framework Directive 111 (WFD), to prevent impairment of 'protected areas' (i.e. including bathing and shellfish 112 harvesting waters), is generating an imperative for the development of modelling 113 capacity. This is needed in order to differentiate specific (spatial) effects of land 114 management practices when combined with catchment responses to hydrological 115 drivers at relevant timescales. However, such models need to account for the source 116 strength of faecal reservoirs attributed to different livestock types and while the 117 current evidence-base is growing it remains far from satisfactory. From a UK 118 perspective there is an urgent need for an inventory of $E$. coli concentrations 119 associated with a suite of livestock types for different regions where livestock farming 120 dominates. However, rather than a comprehensive evidence-base that captures 121 variability of regional E. coli counts, there are few studies that provide useful 122 information (e.g. Avery et al., 2004; Hodgson et al., 2009), and arguably not enough 123 for widespread spatial and temporal modelling of FIO accumulation on pasture. This 124 situation is not unique to the UK. For example, Moriarty et al (2008) highlighted the 125 dearth of published counts of bacterial indicators in fresh livestock faeces across 126 New Zealand and in response undertook a faecal survey across four farm 127 environments spanning the North and South Islands. With limited national data, 128 those who aim to develop microbial fate and transfer models must either undertake 129 faecal surveys as per Moriarty et al (2008) or instead draw on microbial counts 
E. coli variability in fresh dairy faeces

130 published in the wider international literature. Of course, these latter values may not

131 be particularly relevant to local conditions.

132

133 Clearly a national inventory of typical FIO counts would take time to evolve and

134 necessitate significant effort to develop. However, the need for better quality

135 information and a robust empirical evidence-base on FIO concentrations for different

136 geographical areas, livestock types and seasons, is fundamental for underpinning

137 our understanding of diffuse microbial pollution from agriculture (and informing

138 mitigation strategies to reduce its impact). Similar issues have been raised with

139 regard to knowledge of the likely FIO concentrations in raw sewage and treated

140 effluents. Kay et al (2008) identified that few empirical data had been published in the

141 peer reviewed literature for these effluent types and provided a summary of FIO

142 concentrations determined from 162 sewage discharge sites across the UK and

143 Jersey, and stressed the importance of this data for prioritising suitable management

144 approaches to water quality protection.

145

146 Without a thorough understanding of how the burden of FIOs on pasture varies

147 through an annual cycle (and its susceptibility to vary year-on-year) our landscape-

148 level models of microbial fate and transfer are immediately disadvantaged in terms of

149 their predictive capability. This study was therefore designed to contribute important 150 information on FIO concentrations in dairy faeces - one of the key sources of diffuse

151 microbial pollution from agricultural landscapes. The aim of the study was to quantify

152 seasonal, within-herd and year-on-year variability of FIO (both E. coli and other

153 coliform) concentrations in freshly excreted dairy faeces from a typical farm

154 enterprise in central Scotland.

155

156 Results and Discussion 


\section{E. coli variability in fresh dairy faeces}

157 This study provides a significant dataset relating to the potential for $E$. coli and 158 coliform loading to agricultural land by dairy cattle in central Scotland. By following 159 the same herd over a two year period the study has documented the temporal profile 160 of this variability and highlighted: (i) seasonal impacts on the magnitude of $E$. coli 161 excreted in fresh faeces of dairy cows; and (ii) how seasonal shedding patterns can 162 fluctuate over successive years. The importance of FIO concentration data in fresh 163 faeces cannot be understated as it provides information that is crucial for the 164 parameterization of models that aim to predict pathogen and FIO fate and transfer in 165 agricultural catchments (Moriarty et al., 2008; Oladeinde et al., 2014). All microbial counts are presented on a fresh and dry weight basis to enable a wider comparison

167 across the literature. All E. coli counts, and all but the spring 2012 combined coliform counts were confirmed as being log-normally distributed (see Table 1 for normality assessment on the fresh weight counts using the Shapiro-Wilk test).

171 All method blanks were negative for FIOs indicating no cross contamination during 172 sample processing. The mean concentration of $E$. coli determined in fresh dairy

173 faeces for all samples collected across all seasons was found to be 6.63 and 6.58 $174 \log _{10}$ CFU g-1 dry weight for 2012 and 2013, respectively. Interestingly, Martinez et al 175 (2013) reported that the average E. coli concentration in fresh faecal material (based 176 on combined data from six international studies) equated to $6.5 \log _{10} \mathrm{CFU} \mathrm{g^{-1 }}$, which 177 is close to the average values recorded in both years of this study. A series of 178 boxplots are presented in Figure 1 to highlight the contrasting variability in 179 concentrations of $E$. coli excreted in dairy faeces across different seasons over the 180 two-year period, with magnitudes represented on a dry weight basis. Table 1 shows 181 the counts (mean, min and max) for both $E$. coli and a combined coliform count ( $E$. 182 coli plus all other non-E. coli coliforms) on a wet weight basis for comparison. There 183 was little difference in the representation of E. coli and combined coliform counts and 
E. coli variability in fresh dairy faeces

184

185

186

187

188

so the statistical analysis focused on the E. coli counts for brevity. With all data combined, a two-way ANOVA identified a significant difference between the counts determined for different seasons $(P<0.001)$ but not for the overall mean of $E$. coli counts observed in successive years. In 2012 the counts associated with winter faecal deposits (mean of $5.72 \log _{10}$ CFU g-1 dry weight) were significantly lower ( $P$ $<0.05$ ) than those determined in spring, summer and autumn faecal deposits (mean of $6.90,6.79$ and $7.10 \log _{10} \mathrm{CFU} \mathrm{g}^{-1}$ dry weight, respectively). While the overall mean of $E$. coli concentrations did not differ between 2012 and 2013 it was revealed that seasonal differences in 2013 did not mirror those observed in 2012. In 2013 autumn and winter faecal deposits were both found to have significantly lower counts of $E$. coli (mean of 6.25 and $6.16 \log _{10} \mathrm{CFU} \mathrm{g}{ }^{-1}$ dry weight, respectively) relative to summer $\left(P<0.05\right.$; mean count of $7.37 \log _{10} \mathrm{CFU} \mathrm{g} \mathrm{g}^{-1}$ dry weight) but were not significantly lower than those recorded in spring (see Fig 1).

A number of studies have been published that report, to varying extents, on concentrations of FIOs in fresh cattle faeces in New Zealand (Moriarty et al., 2008; Sinton et al; Donnison et al., 2008; Muirhead and Littlejohn, 2009), the US (Weaver et al., 2005; van Kessel et al., 2007; Soupir et al., 2008), Canada (Meays et al., 2005), Australia (Cox et al., 2005) and the UK (Avery et al., 2004; Hodgson et al., 2009). All of these studies report variability in concentrations of FIOs in fresh faeces, often in excess of at least 1 order of magnitude and this result is consistent with the data reported in this current study. There are contrasting observations evident in the international literature with studies reporting peak concentrations of FIOs associated with different seasons (e.g. Sinton et al., 2007; Moriarty et al., 2008; Muirhead and Littlejohn, 2009). Differences in observations at a national level may reflect variations in dietary supplements available to livestock during housing periods (Russell et al., 2000) or anxiety levels of livestock associated with management regimes (Bach et 


\section{E. coli variability in fresh dairy faeces}

211 al., 2004). Studies also vary in their use of 'naturally' deposited cowpats versus 212 artificially homogenized fresh faecal material crafted into replicate cowpats and this 213 may also play a role in the observed variability. For example, recent research by 214 Martinez et al. (2013) analyzed data on FIOs in fresh cowpats obtained from a 215 number of studies at different locations across the world and identified that repacked 216 cowpats had a significantly higher E. coli content than naturally intact cowpats. The 217 same authors also reported that, using this combined international dataset, artificial 218 repacked cowpats exhibited relatively small differences in initial concentrations of $E$. 219 coli in cowpats across different seasons compared to seasonal differences observed 220 in their naturally intact counterparts.

222 The results of the current study confirm that in 2012, autumn $>$ spring $>$ summer $>$ 223 winter with regard to the concentrations of $E$. coli detected in fresh dairy faeces on 224 the monitored farm in Scotland. For 2013 this ranking shifted to summer > spring > 225 autumn $>$ winter. Two observations are clear from an inspection of these seasonal 226 rankings: (i) patterns and seasonal peaks of $E$. coli shedding by dairy cattle are not 227 consistent year on year; but (ii) winter does appear to be somewhat consistent in 228 generating dairy faeces with substantially lower $E$. coli counts relative to other 229 seasons (for a two year cycle at least). The apparent shifts in ranking of seasonal $E$. 230 coli shedding for this study in Scotland may reflect local conditions linked to diet and 231 management that were indirectly impacted by weather conditions. While climatic 232 variables (e.g. temperature and rainfall) cannot be held directly accountable for fresh

233 E. coli concentrations in faeces, because the cells will be held within the animal gut 234 and gastrointestinal tract at $37^{\circ} \mathrm{C}$ prior to excretion, such environmental factors might 235 influence on-farm management decisions (e.g. changes in grazing management that 236 necessitate a shift in livestock diet) that may then have consequential impacts on $E$. coli shedding by cattle. 
E. coli variability in fresh dairy faeces

239 For example in this study, during 2012, dairy cattle were put out to pasture for

240 grazing at the end of April (i.e. mid-spring) but were re-housed relatively early (i.e.

241 July; mid-summer) because of exceptionally wet conditions that rendered grazing

242 activity detrimental to soil and pasture quality. Indeed, summer 2012 ranked as the

243 second wettest in the UK since records began in 1910 and $121 \%$ of the 1961 to 1990

244 UK average rainfall was recorded during 2012 (MET Office, 2012). The cattle were

245 reintroduced to pasture later in the summer of 2012 and grazed until early

246 September before being rehoused again for autumn and winter. In contrast, the 2013

247 grazing regime was more straightforward with cattle grazing from the end of April

248 through to the beginning of October. The diet of the cows was necessarily different

249 during the contrasting grazing and housed periods. During grazing, the dietary intake

250 of cattle was predominantly perennial ryegrass Lolium perenne and this was

251 supplemented with dairy cake (an 18\% protein mix containing wheat and distiller's

252 grains) during milking. During the housed period, their diet consisted mainly of silage

253 combined with distiller's grains, brewer's barley and molasses, and again this was

254 supplemented with dairy cake (at an increased $20 \%$ protein mix) during milking.

255 Given that the winter period in both years resulted in the lowest counts of $E$. coli in

256 fresh dairy faeces it is possible that the housed diet of predominantly silage helped to

257 reduce generic $E$. coli levels excreted, or at least rendered a proportion as viable-but-

258 non-culturable. In a comparison of faeces excreted from silage- and pasture-fed

259 cows the concentrations of $E$. coli have been shown to be lower (by $\sim 1$ order of

260 magnitude) and more variable for those given a silage diet (Donnison et al., 2008).

261 The fermentation process typical of silage production results in the generation of

262 acids, such as lactic acid, that preserves the silage and the resulting reduction in

263 rumen $\mathrm{pH}$ can reduce naturally occurring $E$. coli that do not grow well at low $\mathrm{pH}$

264 values (Russell et al., 2000). In addition, Donnison et al. (2008) hypothesise that the 
E. coli variability in fresh dairy faeces

265

266

267

268

269

270

271

272

273

274

275

higher counts associated with pasture-fed diet may reflect a continuous ingestion of FIOs from faecally contaminated pasture. Interestingly, the 2012 summer FIO concentrations ranked lower relative to their 2013 ranking and this might reflect the removal of the cows from a pasture-fed diet to one of silage during their temporary summer housing because of the exceptionally wet weather in 2012 which was not repeated in 2013.

Statistical analysis using a paired $t$-test on duplicate samples taken from 40 cowpats across all seasons recorded no significant difference $(P=0.58)$ in $E$. coli counts. This suggests that faecal excretion by dairy cattle is effective in homogenizing $E$. coli populations in the faecal matrix and supports the hypothesis that FIOs are thoroughly mixed following faecal passage through the ruminant digestive system and gut. This contrasts with observations for specific pathogens such as E. coli O157 (Robinson et al., 2005) where cells remain heterogeneously distributed within the faeces. The mean \%DM of fresh dairy faeces for all samples collected across all seasons was $13.83 \%$ and $13.22 \%$ for 2012 and 2013 , respectively. The underlying dry matter content of all faecal deposits is presented in Table 2 (mean, median and range) and the variability in \% dry matter is shown in Figure 2 for all seasons across both years. For all data combined, two-way ANOVA identified a significant difference between the $\%$ dry matter determined in different seasons $(P<0.001)$ but there was no significant difference for the overall mean of \%DM recorded across all seasons in 2012 versus 2013. In 2012 the faecal deposits excreted in summer had a significantly lower $(P<0.05)$ DM than those excreted in all other seasons. In 2013 differences in faecal pat DM across seasons were more complex (see Fig 2) although the summer deposits still retained a significantly lower \%DM relative to all other seasons $(P<0.05)$ despite accommodating the largest range of \%DM recorded across both years of the study. No correlation between \%DM content and FIO 


\section{E. coli variability in fresh dairy faeces}

292 catchments.

concentrations in fresh dairy faeces was observed. Moriarty et al (2008) observed a consistent increase in total solid content of fresh dairy faeces from spring to winter and found the winter total solids content to be approximately double that observed in faeces excreted in spring. In our study this pattern was not observed and for both 2012 and 2013 the faeces excreted in summer contained the lowest dry matter content. The lower DM in summer is probably a consequence of diet with pasture forming the predominant source of feed. The higher DM in winter through spring is likely to reflect the diet shift from pasture to silage.

The empirical data reported in this study has highlighted considerable variability in $E$. coli and coliform concentrations and their susceptibility to change seasonally, both between and within annual cycles. This has important implications for modeling approaches that choose to use a single parameter for an E. coli concentration typical of dairy faeces (and most probably other faeces associated with other livestock types too) without considering (i) within-herd variation in shedding and (ii) how this seasonal shift in variability might impact on predictions of FIO risk dynamics over time for a given area. Studies such as the one presented here need to be repeated across different regions of the UK to build up a better profile of how FIO concentrations vary spatially and in time. Developing an inventory of microbial magnitudes in fresh faeces and improving our understanding of their scope to vary is an important factor to build into modeling approaches and to communicate to catchment stakeholders interested in microbial risks associated with land and water. 
E. coli variability in fresh dairy faeces

\section{Materials and Methods}

\section{Sample collection}

321 Ten fresh dairy cowpats were collected on eight sampling occasions over a two year

322 period. Samples were collected in March, June, September and December of 2012

323 and 2013 and represented faeces excreted at the start of each season (spring,

324 summer, autumn and winter, in the northern hemisphere). The ten cowpats served

325 as replicate samples and were collected from ten different cows on each sampling

326 occasion. Thus, a total of 80 cowpats were collected throughout the study period.

327 The cowpats were collected from a single conventional 165 ha dairy farm in

328 Stirlingshire, Scotland. The dairy herd totaled 80 head of cattle, was normally housed

329 from October through to the end of March, and produced an average of 8000 litres of

330 milk per year per cow. All cowpats were collected within 30 minutes of excretion.

331 Fresh samples were collected from a covered holding-barn that was used during the

332 transfer of dairy cows to the parlour for morning milking. This barn was scraped clean

333 twice daily and so all cowpats collected were assured to be fresh deposits.

335 All cowpats were collected from Holstein Friesians used for milk production and were

336 sampled and analysed for Escherichia coli, coliforms, and dry matter (DM) content.

337 Microbial analysis was initiated within one hour of samples being collected.

338 Approximately $15 \mathrm{~g}$ of faeces was randomly sampled from each cowpat using a 339 sterile spatula (70\% IMS, rinsed with sterile water) and placed into sterile $50 \mathrm{~mL}$

340 centrifuge tubes. Samples were assumed to be well mixed and homogeneous

341 following faecal passage through the ruminant digestive system and gut. However,

342 for $50 \%$ of the cowpats, a duplicate random sample was taken from the faeces to 343 investigate whether the sampling approach could potentially impact on recorded FIO 344 counts because of uneven distribution of cells within the faecal matrix (i.e. spatial 345 bias in counts). Only the original sample was used in the wider analysis reported in 
E. coli variability in fresh dairy faeces

346 this study but the duplicate sample served an important purpose as a subcomponent

347 of this faecal survey, as described.

Sample analysis

350 One gram of fresh faeces was used for microbial analysis and the remainder was

351 used to determine the gravimetric water content by drying at $105^{\circ} \mathrm{C}$ for $24 \mathrm{~h}$ (until 352 constant mass) and weighing the residual. For microbial analysis, one gram of 353 faeces was transferred to $9 \mathrm{~mL}$ of sterile phosphate buffered saline (PBS) and then 354 thoroughly mixed using an orbital shaker (160 rpm for 60 minutes at ambient 355 temperature) to disperse cells from the faecal matrix. Further serial 1:10 dilutions 356 were then made as appropriate to ensure capture of between 20 to 200 colony 357 forming units (CFU) once the sample had been transferred to an agar growth 358 medium. To get to this stage, $1 \mathrm{~mL}$ of each serially-diluted sample was washed 359 through a filtration unit (Sartorius, Germany) with $\sim 20 \mathrm{~mL}$ of sterile PBS. Membrane 360 filters of 0.45 micron pore size (Sartorius, Germany) were aseptically transferred to 361 Membrane Lactose Glucuronide Agar (MLGA) (Oxoid, Basingstoke, UK) and 362 incubated inverted at $37^{\circ} \mathrm{C}\left( \pm 0.2^{\circ} \mathrm{C}\right)$ for $18-24 \mathrm{~h}$ for the determination of presumptive 363 E. coli and other coliform colonies. Equipment was flame sterilized between samples 364 and method blanks (i.e. sterile PBS) used to confirm the sterilization procedure. The 365 limit of detection was 100 CFU per $\mathrm{g}$ fresh weight faeces.

\section{Statistical Analysis}

368 All counts were transformed to $\log _{10}$ CFU and distributions of $E$. coli were log 369 normally distributed as determined using the Shapiro-Wilk goodness of fit test. 370 Treatment (season, year) differences in E. coli and \%DM were compared by two-way 371 analysis of variance (ANOVA) for all data combined. One-way ANOVA was used to 372 test for differences across individual years and Tukey multiple comparison tests 
E. coli variability in fresh dairy faeces

373 applied (Minitab 12.0 software, Minitab Inc., PA, USA). A paired $t$-test was used to 374 determine whether there was any significant difference between repeated sampling

375 of different sub-components of the same cowpat.

Acknowledgements

378 This study was funded as part of research grant NE/J004456/1, awarded to DMO by 379 the Natural Environment Research Council. DMO is grateful for the cooperation of 380 the dairy farm for provision of records and access to the herd for sampling. The constructive comments of the anonymous referees helped to improve the quality of 382 the manuscript.

\section{Conflicts of interest}

385 No conflict of interest declared.

References

Avery, S. M., Moore, A., and Hutchison, M. L. (2004) Fate of Escherichia coli originating from livestock faeces deposited directly onto pasture. Lett Appl

Bach, S. J., McAllister, T. A., Mears, G. J., and Schwartzkopf-Genswein, K. S. (2004) Long-haul transport and lack of preconditioning increases fecal shedding of Escherichia coli and Escherichia coli $\mathrm{O} 157$ by calves. J Food Protection 67, 672-678. 569- 578.

398 Chadwick, D., Fish, R., Oliver, D. M., Heathwaite, L., Hodgson, C. and Winter, D. M. 399 (2008) Management of livestock and their manure to reduce the risk of 
E. coli variability in fresh dairy faeces

microbial transfers to water: the case for an interdisciplinary approach. Trends Food Sci.Tech 19, 240-247.

Cox, P., Griffith, M., Angles, M., Deere, D., and Ferguson, C. (2005) Concentrations of pathogens and indicators in animal feces in the Sydney watershed. Appl Env Microbiol 71, 5929-5934.

Donnison, A., Ross, C., and Clark, D. (2008) Escherichia coli shedding by dairy cows. NZ J Agric Res 51, 273-278.

Ferguson, C. M., Charles, K., and Deere, D. A. (2009) Quantification of microbial sources in drinking-water catchments. Crit Rev Env Sci Tech 39, 1-40.

Hodgson, C. J., Bulmer, N., Chadwick, D. R., Oliver, D. M., Heathwaite, A. L., Fish, R. D., and Winter, M. (2009) Establishing relative release kinetics of faecal indicator organisms from different faecal matrices. Lett Appl Microbiol 49, 124-130.

Kay, D., Crowther, J., Stapleton, C. M., Wyer, M. D., Fewtrell, L., Edwards, A., Francis, C. A., McDonald, A. T., Watkins, J., and Wilkinson, J. (2008) Faecal indicator organism concentrations in sewage and treated effluent. Water Res 42, 442-454.

Martinez, G., Pachepsky, Y. A., Shelton, D. R., Whelan, G., Zepp, R., Molina, M., and Panhorst, K. (2013) Usisng the $Q_{10}$ model to simulate E. coli survival in cowpats on grazing lands. Env Int 54, 1-10.

Meays, C. L., Broersma, K., Nordin, R., and Mazumder, A. (2005) Survival of Escherichia coli in beef cattle fecal pats under different levels of solar exposure. Rangeland Ecol. Manage 58, 279-283.

MET Office (2012). Regional annual summaries of UK rainfall 2012 http://www.metoffice.gov.uk/climate/uk/summaries/2012/annual/regionalvalues. Accessed 29th January 2014. 
E. coli variability in fresh dairy faeces

Moriarty, E. M., Sinton, L. W., Mackenzie, M. L., Karki, N., and Wood, D. R. (2008) A survey of enteric bacteria and protozoans in fresh bovine faeces on New Zealand dairy farms. J Appl Microbiol 105, 2015-2025.

Muirhead, R. W., Collins, R. P. and Bremer, P. J. (2006) Numbers and transported state of Escherichia coli in runoff direct from fresh cowpats under simulated rainfall. Lett Appl Microbiol 42, 83-87.

Muirhead, R. W., and Littlejohn, R. P. (2009) Die-off of Escherichia coli in intact and disrupted cowpats. Soil Use Manage 25, 389-394.

Oladeinde, A., Bohrmann, T., Wong, K., Purucker, S. T., Bradshaw, K., Brown, R., Snyder, B., and Molina, M. (2014) Decay of fecal indicator bacterial populations and bovine-associated source-tracking markers in freshly deposited cow pats. Appl Env Microbiol 80, 110-118.

Oliver, D. M., Page, T., Heathwaite, A. L., and Haygarth, P. M. (2010a) Re-shaping models of $E$. coli population dynamics in livestock faeces: increased bacterial risk to humans? Env Int 36, 1-7.

Oliver, D. M., Page, T., Hodgson, C. J., Heathwaite, A. L., Chadwick, D. R., Fish, R. D., and Winter, M. (2010b) Development and testing of a risk indexing framework to determine field scale critical source areas of faecal bacteria on grassland. Environ Model Software 25, 503-512.

Oliver, D. M., Page, T., Zhang, T., Heathwaite, A. L., Beven, K., Carter, H., McShane, G., Keenan, P. O., and Haygarth, P. M. (2012) Determining E. coli burden on pasture in a headwater catchment: combined field and modelling approach. Env Int 43, 6-12.

Robinson, S. E., Brown, P. E., Wright, E. J., Bennett, M., Hart, C. A., and French, N. P. (2005). Heterogeneous distributions of Escherichia coli 0157 within naturally infected bovine faecal pats. FEMS Microbiol Lett 244, 291-296. 
E. coli variability in fresh dairy faeces

452 Russell, J. B., Diez-Gonzalez, F., and Jarvis, G. N. (2000) Effects of diet shifts on Escherichia coli in cattle. J Dairy Sci 83, 863-873.

454 Sinton, L. W., Braithwaite, R. R., Hall, C. H., and Mackenzie, M. L. (2007) Survival of 455 indicator bacteria in bovine feces on pasture. Appl Environ Microbiol 73, 7917-7925.

457 Soupir, A. L., Mostaghimi, S., and Lou, J. (2008) Die-off of E. coli and enterococci in 458 dairy cowpats. Trans. ASABE 51, 1987-1996

459 Van Kessel, J. S., Pachepsky, Y. A., Shelton, D. R., and Karns, J. S. (2007) Survival 460 of Escherichia coli in cowpats in pasture and in laboratory conditions. $J$ Appl. 461 Microbiol 103, 1122-1127.

462 Weaver, R. W., Entry, J. A., and Graves, A. (2005) Numbers of fecal streptococci 463 and Escherichia coli in fresh and dry cattle, horse, and sheep manure. Canadian J Microbiol 51, 847-851.

465 Wu J., Long S. C, Das D., Dorner S. M. (2011) Are microbial indicators and 466 pathogens correlated? A statistical analysis of 40 years of research. $J$ Water Health 9, 265-278.

468

469

470

471

472

473 
E. coli variability in fresh dairy faeces

\section{List of Figures}

477

478

479

480

481

482

483

484

485

486

487

488

489

490

491

492

493

494

495

496

497

498

499

500

501

Fig 1: Seasonal, within-herd and year-on-year variability of $E$. coli concentrations in fresh dairy faeces. Boxplots with different letter codes differ significantly from one another (2012 data: one-way ANOVA, $P<0.001$; Tukey multiple comparison test, $P<$ 0.05 \& 2013 data: one-way ANOVA , $P=0.016$; Tukey multiple comparison test, $P<$ 0.05). Centre horizontal dash, box and whiskers represent median, inter-quartile range and upper \& lower limits, respectively. Values are the mean of 10 replicates.

Fig 2: Seasonal, within-herd and year-on-year variability of \% dry matter content in fresh dairy faeces. Boxplots with different letter codes differ significantly from one another (2012 data: one-way ANOVA, $P<0.001$; Tukey multiple comparison test, $P<$ 0.05 \& 2013 data: one-way ANOVA, $P<0.001$; Tukey multiple comparison test, $P<$ 0.05). Centre horizontal dash, box and whiskers represent median, inter-quartile range and upper \& lower limits, respectively. ${ }^{*}$ signifies an extreme value. Values are the mean of 10 replicates. (1) 
Table 1: Summary of $E$. coli and combined coliform counts (E. coli + other non-E. coli coliform bacteria) on a wet weight basis. All counts

503 derived from 10 cowpats per sampling event.

\begin{tabular}{|c|c|c|c|c|c|c|c|c|}
\hline \multirow[t]{2}{*}{$\begin{array}{l}\text { Sampling } \\
\text { date }\end{array}$} & \multicolumn{3}{|c|}{ E. coli $\left(\log _{10} \mathrm{CFU} \mathrm{g^{-1 }}\right.$ wet weight) } & \multicolumn{3}{|c|}{$\begin{array}{l}\text { Combined coliforms (log }{ }_{10} \\
\text { CFU g-1 wet weight) }\end{array}$} & \multirow{2}{*}{$\begin{array}{c}\text { E. coli } \\
\\
P \text { value (Sig } \\
\text { different to } \\
\text { Lognormal } \\
\text { distribution?) } \\
\end{array}$} & \multirow{2}{*}{$\begin{array}{c}\text { All coliforms } \\
\boldsymbol{P} \text { value (Sig } \\
\text { different to } \\
\text { Lognormal } \\
\text { distribution?) }\end{array}$} \\
\hline & Mean & Min & Max & Mean & Min & Max & & \\
\hline $\begin{array}{l}\text { Spring } \\
2012\end{array}$ & 6.07 & 5.22 & 7.47 & 6.27 & 5.49 & 7.82 & $>0.10$ & $<0.01$ \\
\hline $\begin{array}{l}\text { Summer } \\
2012\end{array}$ & 5.87 & 5.03 & 6.56 & 6.89 & 6.06 & 7.61 & $>0.10$ & $>0.15$ \\
\hline $\begin{array}{l}\text { Autumn } \\
2012\end{array}$ & 6.24 & 5.38 & 6.97 & 6.28 & 5.40 & 7.00 & $>0.10$ & $>0.15$ \\
\hline $\begin{array}{l}\text { Winter } \\
2012\end{array}$ & 4.87 & 3.54 & 6.40 & 4.90 & 3.54 & 6.52 & $>0.08$ & 0.11 \\
\hline $\begin{array}{l}\text { Spring } \\
2013\end{array}$ & 5.69 & 3.84 & 7.03 & 5.69 & 3.84 & 7.03 & $>0.10$ & $>0.15$ \\
\hline $\begin{array}{l}\text { Summer } \\
2013\end{array}$ & 6.89 & 6.02 & 8.44 & 6.91 & 6.04 & 8.44 & $>0.10$ & $>0.15$ \\
\hline $\begin{array}{l}\text { Autumn } \\
2013\end{array}$ & 5.34 & 4.54 & 6.84 & 5.38 & 4.55 & 6.84 & $>0.10$ & $>0.15$ \\
\hline $\begin{array}{l}\text { Winter } \\
2013\end{array}$ & 5.74 & 4.51 & 7.12 & 5.81 & 4.83 & 7.12 & $>0.10$ & $>0.15$ \\
\hline
\end{tabular}


E. coli variability in fresh dairy faeces

504

505 506

Table 2: Dry matter (DM) content of dairy faeces collected throughout the 2 year study. All counts derived from 10 cowpats per sampling event.

\section{Sampling date $\quad$ Mean \% DM Median \% DM Range of \% DM (magnitude)}

\begin{tabular}{llll}
\hline Spring 2012 & 15.19 & 15.16 & $13.96-16.99(3.04)$ \\
Summer 2012 & 11.95 & 11.82 & $9.72-14.52(4.80)$ \\
Autumn 2012 & 14.07 & 13.93 & $11.97-18.31(6.33)$ \\
Winter 2012 & 14.10 & 13.90 & $13.03-15.26(2.23)$ \\
Spring 2013 & 13.92 & 13.86 & $12.34-15.55(3.21)$ \\
Summer 2013 & 11.85 & 11.54 & $9.25-17.44(8.19)$ \\
Autumn 2013 & 12.35 & 12.21 & $9.89-14.25(4.36)$ \\
Winter 2013 & 14.76 & 14.35 & $13.28-17.42(4.14)$ \\
\hline
\end{tabular}

507

508

509

510

511

512

513

514

515

516

517

518

519

520

521

522

523 


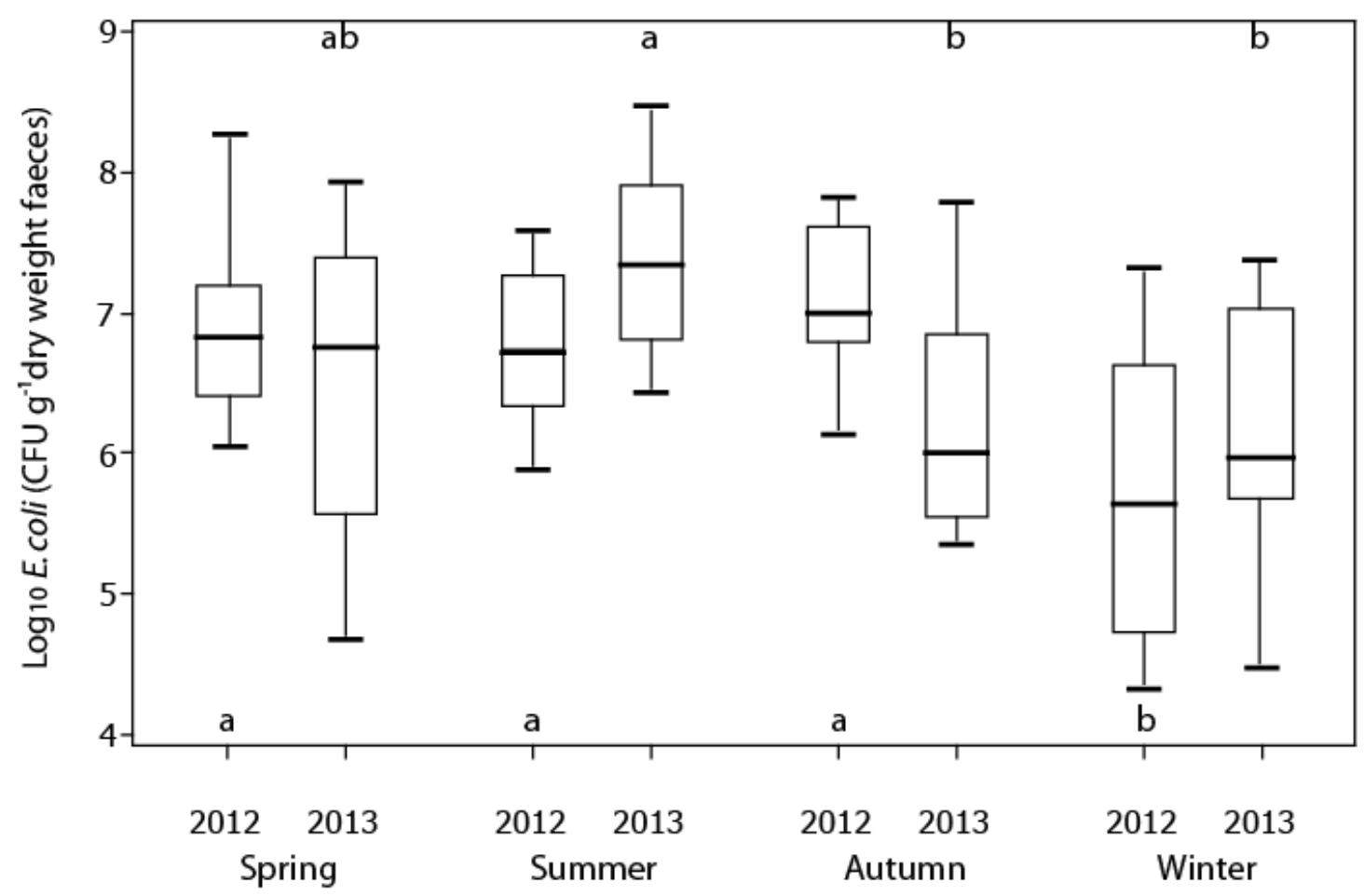

Fig 1: Seasonal, within-herd and year-on-year variability of $E$. coli concentrations in fresh dairy faeces. Boxplots with different letter codes differ significantly from one another (2012 data: one-way ANOVA, $P<0.001$; Tukey multiple comparison test, $P<$ 0.05 \& 2013 data: one-way ANOVA, $P=0.016$; Tukey multiple comparison test, $P<$ $0.05)$. Centre horizontal dash, box and whiskers represent median, inter-quartile range and upper \& lower limits, respectively. Values are the mean of 10 replicates. 


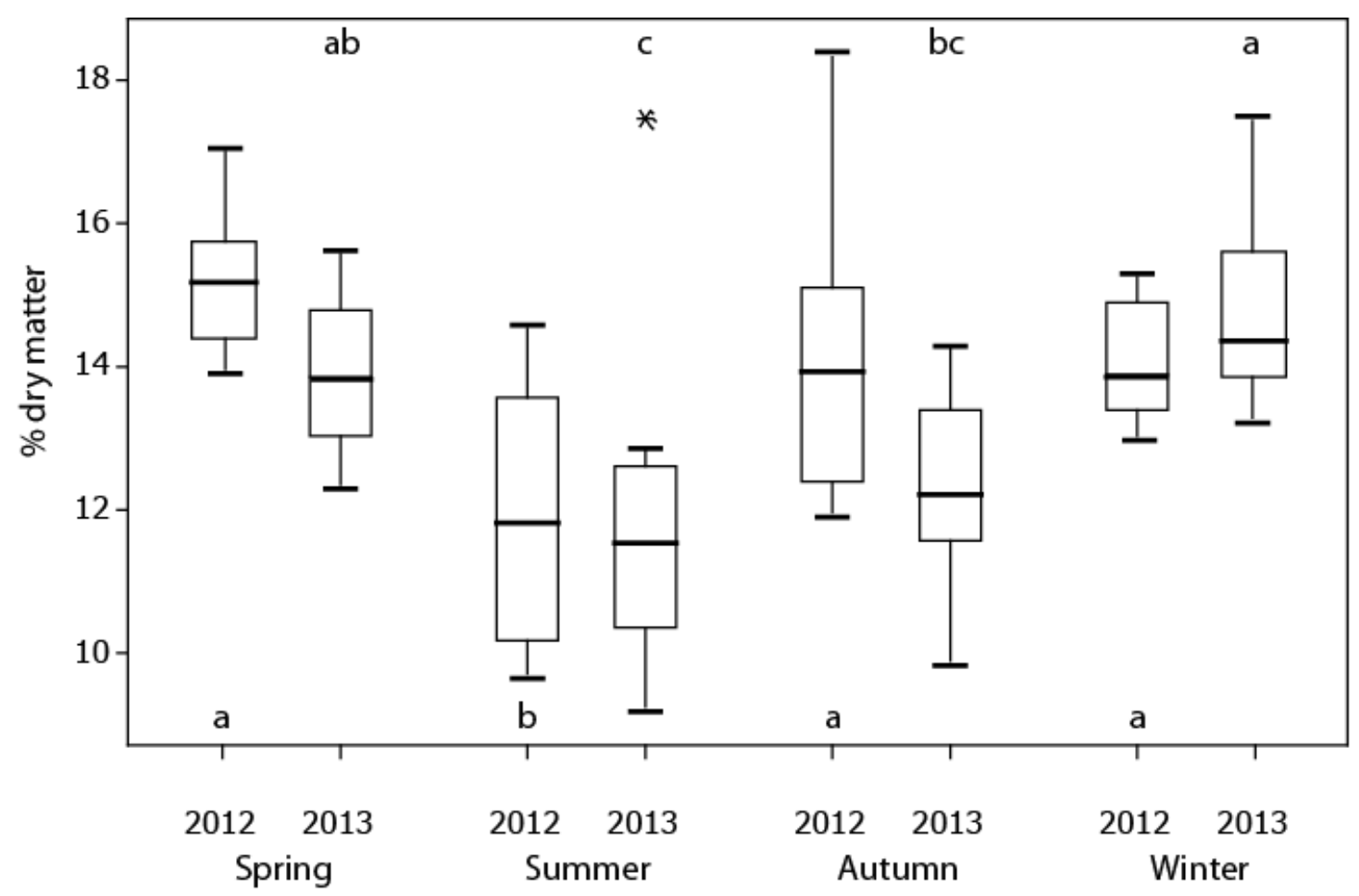

Fig 2: Seasonal, within-herd and year-on-year variability of \% dry matter content in fresh dairy faeces. Boxplots with different letter codes differ significantly from one another (2012 data: one-way ANOVA, $P<0.001$; Tukey multiple comparison test, $P<$ 0.05 \& 2013 data: one-way ANOVA, $P<0.001$; Tukey multiple comparison test, $P<$ $0.05)$. Centre horizontal dash, box and whiskers represent median, inter-quartile range and upper \& lower limits, respectively. ${ }^{*}$ signifies an extreme value. Values are the mean of 10 replicates. 